\title{
Selective and Sensitive Simultaneous Determination of Mercury and Cadmium based on the Aggregation of PHCA Modified-AuNPs in West Azerbaijan Regional Waters
}

\author{
Sakineh Alizadeh ${ }^{\mathrm{a}, *}$, Tayyebeh Madrakian ${ }^{\mathrm{a}}$, Morteza Bahram ${ }^{\mathrm{b}}$
}

\section{ART I C L E IN F O}

Received: 2 December 2018 Revised: 19 December 2018 Accepted: 28 December 2018 Available online: 6 January 2019

\section{K E Y W O R D S}

\section{Cadmium}

Mercury

Gold Nanoparticles

Simultaneous Determination

Multivariate Analysis

\section{A B S T R A C T}

The present study aims to present a new convenient sensor for heavy metals, based on aggregation of citrate-capped-N, N' biphenyl hydrazine 1, 2 dicarbothioamide (PHCA) - modified- (AuNPs). This paper reports a procedure for sensitive and selective spectrophotometric methods for simultaneous determination of mercury $\left(\mathrm{Hg}_{2}{ }^{2+}\right)$ and cadmium $\left(\mathrm{Cd}^{2+}\right)$. For this aim multivariate data including kinetic spectra of AuNPs were collected during aggregation process. The characterization of AuNPs was performed by transmission electron microscopy (TEM) and Infra-Red (IR) spectroscopy. Partial least square (PLS) regression as an efficient multivariate calibration method was employed to make a connection between the surface plasmon resonance (SPR) spectra of the generated AuNPs. The number of PLS latent variables was optimized by leave-one-out cross-validation utilizing prediction residual error sum of square (PRESS). The linear range was in the range of $3.33 \times 10^{-5}-3.33 \times 10^{-6} \mathrm{~mol} \mathrm{~L}^{-1}$ and $2.0 \times 10^{-5}-1.0 \times 10^{-6}$ mol L ${ }^{-1}$, the detection limit was $1.21 \times 10^{-7}$ and $0.5 \times 10^{-7} \mathrm{~mol} \mathrm{~L}^{-1}(\mathrm{n}=5)$ for $\mathrm{Hg}_{2}{ }^{2+}$ and $\mathrm{Cd}^{2+}$, respectively. This method used successfully for simultaneous determination of $\mathrm{Hg}_{2}{ }^{2+}$ and $\mathrm{Cd}^{2+}$ in West Azerbaijan regional waters namely Zarineh / Simineh rivers and Urmia lake.

\section{GR A P H I C A L A B S T RACT}
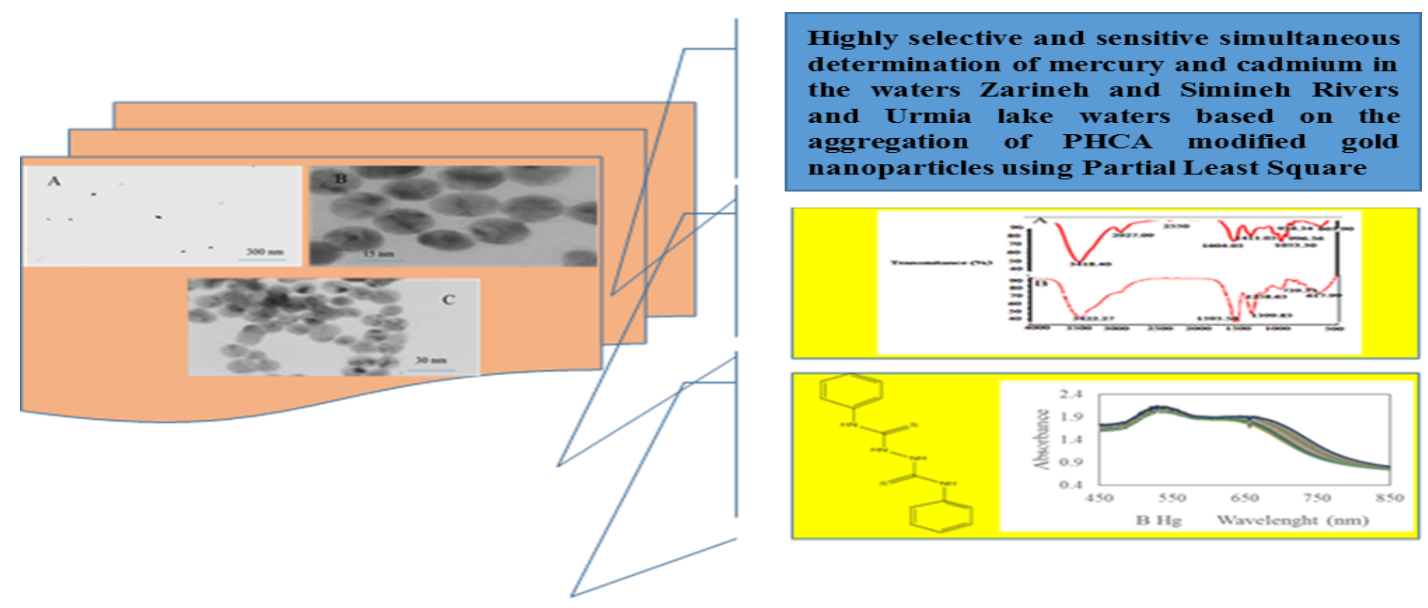

\footnotetext{
*Corresponding author's E-mail address: solmaz.alizade@gmail.com, Tel.: 00984412972143

${ }^{a}$ Department of Analytical chemistry, Faculty of Chemistry, Bu-Ali Sina University, 65178638695, Hamadan, Iran

${ }^{\mathrm{b}}$ Department of chemistry, Faculty of Science, Urmia University, 5715175976, Urmia
} 


\section{Introduction}

Our green planet is progressively contaminated by different contaminants. Heavy metals can be considered as one of the most serious contaminant groups which have been released in the biosphere by human activities. Industrial activities, energy production, construction, urban waste treatment, and vehicle exhaust are some of the sources causing large quantities of heavy metal contamination in atmosphere, water, and soil [1]. Mercury $\left(\mathrm{Hg}_{2}{ }^{2+}\right)$ and cadmium $\left(\mathrm{Cd}^{2+}\right)$ are among the essential heavy metals .Since many years ago, Cadmium was used as a corrosionresistant plating on steel and cadmium compounds were used as red, orange and yellow pigments, to color glass and stabilize plastic. Due to its toxic effect cadmium has been listed in the European Restriction of Hazardous Substances

(ERHS), subsequently its usage has been decreased [2-4].

Mercury polycations are polyatomic cations whichcontain only mercury atoms. The best known example is the $\mathrm{Hg}_{2}{ }^{2+}$ ion, found in mercury (I) (mercurous) compounds. The existence of the metal-metal bond in Hg (I) compounds was established using X-ray studies in 1927 [5] and Raman spectroscopy in 1934 [6] making it one of the earliest, if not the first, covalent metal-metal bonds to be characterised. Other mercury polycations are the linear $\mathrm{Hg}_{2}{ }^{3+}$ and $\mathrm{Hg}_{2}{ }^{4+}$ ions [6] and the triangular $\mathrm{Hg}_{4}{ }^{3+}$ ion [7] and a number of chain [8] and layer polycations [9].

Due to the adverse health effects of mercury and cadmium, detection of trace amount of these elements in any environmental sample especially the ones which are related to human being is very important. Determination of these elements requires sufficiently sensitive techniques to detect $\mu \mathrm{g} / \mathrm{L}$ or sublevels. In the literature, there are many techniques including atomic absorption spectrometry (AAS) [10, 11], graphite furnace atomic absorption spectrometry (GFAAS) [12, 13], inductively coupled plasma optical emission spectrometry (ICP-OES) $[14,15]$, and inductively coupled plasma mass spectrometry (ICP-MS) [16, 17] have been sugessted for the determination of $\mathrm{Hg}_{2}{ }^{2+}$ and $\mathrm{Cd}^{2+}$ in various matrices. Although AAS has been used for many elements in variety of matrices $[18,19]$ but the present study uses Au-nanoparticles to study these heavy metals.

Gold nanoparticles (AuNPs) are also useful colorimetric probes because of their distance-dependent optical properties and extremely high extinction coefficients invisible region $[20,21]$ which closely rely on their unique surface plasmon resonance 
(SPR) from red to blue, corresponding to their dispersion and aggregation states [22], respectively.

AuNPsdue to its high stability than other metal nanoparticles is also used invarious fields such as sensors, biosensors, medicine, catalysis and many emerging areas of nanotechnology [23-25].

In order to perform a general analysis on the spectral overlapping of total aflatoxins and their simultaneous determination, chemometric methods must be employed. Recently, chemometric methods such as principal component regression (PCR), partial least square (PLS) and artificial neural network (ANN) have been used frequently for multicomponent determinations [26-28].

PLS regression can allow simultaneous spectrophotometric determination of several ions as well as improve the data handling process of complex chemical systems [29]. PLS calibration of a multicomponent system can be performed in two different ways, $\mathrm{PLS}_{1}$ and $\mathrm{PLS}_{2}$. The use of $\mathrm{PLS}_{2}$ - has a few advantages. Firstly, there is one common set of PLS factors for all analytes. This simplifies the procedure and interpretation and allows for simultaneous graphical inspection. Secondly, when the analyte concentrations are strongly correlated, one may expect that the $\mathrm{PLS}_{2}$ model is more robust than separate $\mathrm{PLS}_{1}$ models. Finally, when the number of analytes is large the a single $\mathrm{PLS}_{2}$ - model develops much quicker than many separate $\mathrm{PLS}_{1}$ models [30].

In this work, new method based on aggregation of citrate-capped Au NPs is presented for highly selective and sensitive simultaneous determination of $\mathrm{Hg}_{2}{ }^{2+}$ and $\mathrm{Cd}^{2+}$. The method is based on the difference in kinetic of aggregation of citrate-capped AuNPs modified with $\mathrm{N}, \mathrm{N}^{\prime}$ biphenyl hydrazine 1, 2 dicarbothioamide (PHCA) in the presence of $\mathrm{Hg}_{2}{ }^{2+}$ and $\mathrm{Cd}^{2+}$. Through adding of $\mathrm{Hg}_{2}{ }^{2+}$ and $\mathrm{Cd}^{2+}$ the absorbance was decreased in $520 \mathrm{~nm}$ and increased in 660 $\mathrm{nm}$. The difference in kinetic profiles of aggregation (monitored absorbance increase versus time in $660 \mathrm{~nm}$ ) was used for simultaneous analysis of $\mathrm{Hg}_{2}{ }^{2+}$ and $\mathrm{Cd}^{2+}$ using PLS regression as an efficient multivariate calibration method.

\section{Experimental}

\section{Computational details}

All materials and reagents were in analytical grade, solvents were of spectroscopic grade and double distilled water (DDW) was used. All chemicals used in the experiment were in analytical grade therefore further purification was no needed. Trisodium citrate dehydrate, $\mathrm{HAuCl}_{4}, \mathrm{HCl}, \mathrm{NaOH}$ were 
obtained from Merck (Darmstadt, 91 Germany).

\section{Apparatus}

Absorption spectra were recorded on an Agilent 8453 UV-Visible spectrophotometer with a $1 \mathrm{~cm}$ quartz cells. The size, morphology and structure of the synthesized AuNPs were characterized by transmission electron microscopy (TEM, Philips-CMC-300 KV). A Metrohm model 713 $\mathrm{pH}$-meter was used for $\mathrm{pH}$ measurements. A $40 \mathrm{kHz}$ universal ultrasonic cleaner water bath (RoHS, Korea) was also used. All calculations and programming were performed in MATLAB (Hyper-cube Inc. Version 10) PLS $\mathrm{m}$ files by the use of essential regression.

\section{Synthesis of AuNPs}

The Au seeds were synthesized according to Ferns method [31]. Briefly, $100 \mathrm{ml}$ of $1 \mathrm{mmol}$ $\mathrm{L}^{-1}$ aqueous solution of $\mathrm{HAuCl}_{4}$ was heated and stirred simultaneously to reach boiling

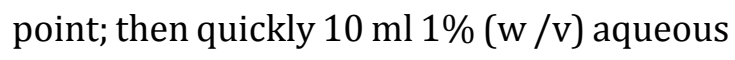
sodium citrate was added. The color of the mixed solution changed from yellow to wine red within a few minutes, indicating the formation of AuNPs. The boiling and stirring were continued for $15 \mathrm{~min}$ [31]. The seed solution was cooled at the room temperature and was stored in a dark bottle at $4^{\circ} \mathrm{C}$. the solution of prepared citratecapped AuNPs (Figure 1) was wine red, and has a characteristic localized surface plasmon resonance (LSPR) absorption band of AuNPs in $520 \mathrm{~nm}\left(\lambda_{\max }\right)$ with narrow peak. In solution, monodisperse AuNPs appeared red and exhibited a relatively narrow surface plasmon absorption band around $520 \mathrm{~nm}$ in the UV-Vis spectrum. In contrast, a solution containing aggregated AuNPs turned blue, corresponding to a characteristic red shift in the surface plasmon resonance to higher wavelength in $660 \mathrm{~nm}[31,32]$. Figure 2 (A-B) shows the IR spectra of synthesized Au Nano particles, before and after aggregation. In IR spectra obviously the functional group of $\mathrm{N}-\mathrm{H}$ (3100-3500 $\mathrm{cm}^{-1}$ and $1400-1700 \mathrm{~cm}^{-1}$ ), $\mathrm{C}=\mathrm{C}$ (1500-1700 $\left.\mathrm{cm}^{-1}\right)$ and $\mathrm{C}=\mathrm{N}$ (1600-1700 $\mathrm{cm}^{-}$ 1) is available which indicates that PHCA had interaction with AuNPs. On the other hand the intensity of IR spectrum when is coated by PHCA or has interaction with nanoparticles decreases and substance functional group region increases.

\section{Water samples preparation}

Water samples were collected from two cities, namely, Miandoab and Urmia located in the west Azerbaijan, Iran. Different sampling points were selected in these cities for homogenous representation of the region. Before sample collection, bottles were rinsed with DDW. One litter from Zarineh and Simineh rivers and Urmia lake 
were collected as water samples for $\mathrm{Hg}_{2}{ }^{2+}$

and $\mathrm{Cd}^{2+}$ determinations.

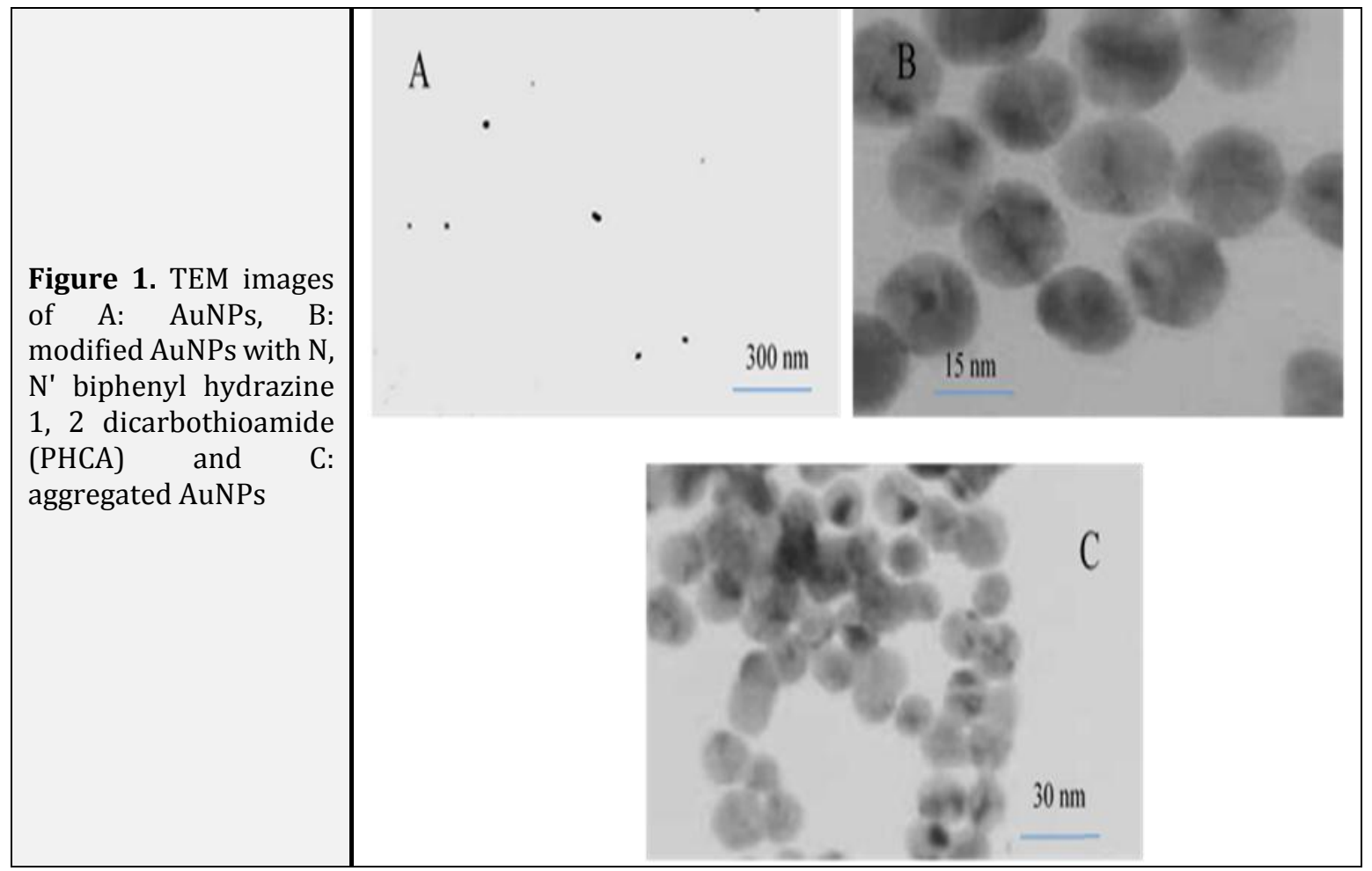

Figure 2. IR spectra of A: AuNPs, B: (PHCA)@ AuNPs in optimum conditions.

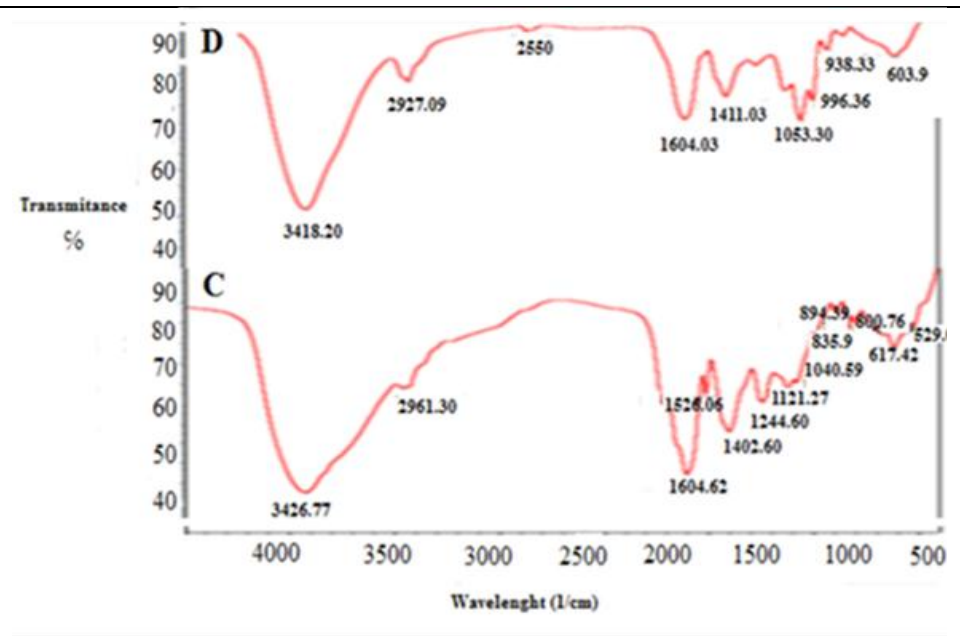

Samples were brought to the laboratory and kept in the fridge before analysis. All of the system parameters were optimized for each analyte to increase the sensitivity. While optimizing, all the parameters were kept constant except one variable at a time.

Results and Discussion 
Optimization of modifying agent Concentration

Modifyingagent (PHCA) (Scheme1) concentration has a crucial role in the aggregation process and that of selectivity agent can be attributed to the ability of modifier to constrict the nanoparticles with special functional group which can selectively complex or get H-bond or other interactions with our substances. Therefore we can take the selective simultaneous determination. Also, it is found that by increasing the modifying agent surface of nanoparticles covered for these reason, the best level of this modifier concentration take the $10^{-5} \mathrm{~mol} \mathrm{~L}^{-1}$ that have ratio of 10 to 20 with detecting substances and don't interfere our substances but can obtain selectivity power with the interactions and aggregation positions [33]. Several ligands with differentdonor atoms have been examined as heavy metal ionophores, in the presence of interfering ions. PHCAdescribed how to switch from a preference for alkali and alkaline earth cations, to a preference for heavy and transition metal cations by replacing hard oxygen-based binding groups with softer sulfur-based binders through considering the affinity of $\mathrm{Hg}^{2+}$ and $\mathrm{Cd}^{2+}$ for soft sulfur atom [34].

\section{Optimization of $\mathrm{NaCl}$ Concentration}

Ion strength has a crucial role in the aggregation process that can be attributed to the ability of strong electrolytes to constrict the aroused electrical double-layer from the capping agent. Also, it is found that by increasing the ion strength above a certain limit, the aggregation of nanoparticles is induced even in the absence of analytes [35]. As can be seen from the Figure 3, $1 \mathrm{mmol} \mathrm{L}^{-1}$ of $\mathrm{NaCl}$ was used as optimized value.

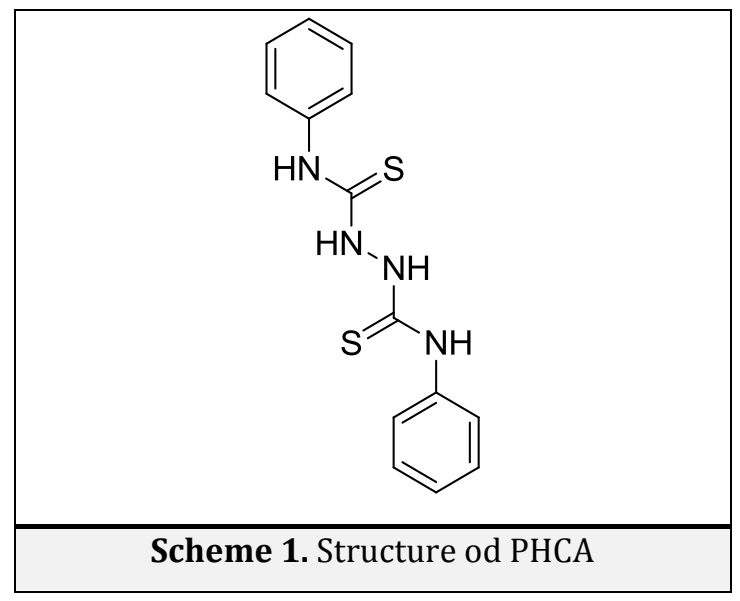

\section{Optimization of $\mathrm{pH}$}

Because of the presence of hydroxyl, carboxyl and amine groups in materials, $\mathrm{pH}$ is another critical parameter that should be taken into consideration. Electrostatic interactions are the mainly responsible for aggregation of AuNPs in the presence of our materials [36]. With this in mind, to increase the possibility of electrostatic interaction, the best condition is attainable in which the ions molecule is available in the nanoparticle surrounding. As shown in Figure 4, the synthesized AuNPs are stable in the range of $\mathrm{pH} 7$ and also the species have 
best structure for interaction with AuNPs in of pH 7 and in basic pHs, these metal ions can change in hydroxide sediment form [37]. Therefore, the pH 7 was chosen for further studies.

\section{Optimization of incubation time}

Different incubation times were examined to find the optimum value. The results indicated that AuNPs after mixing with $\mathrm{Hg}_{2}{ }^{2+}$ and $\mathrm{Cd}^{2+}$ in optimum conditions, was started to aggregate then was suppressed therefore spectral change was detectable in the $10 \mathrm{~min}$ as an optimum incubation time. So we used this range of time as the end time for simultaneous kinetic study Figure 5.

\section{PLS model development}

Partial least square regression (PLSR) calibrations for both ions were constructed by using the non-linear iterative partial least squares (NIPALS) algorithm. A training set of 19 standard samples (14 samples as calibration set and 5 samples as prediction set) was taken from different mixtures of $\mathrm{Hg}_{2}{ }^{2+}$ and $\mathrm{Cd}^{2+}$.

Figure 3. Optimization of ionic strength for A) $\left.\mathrm{Hg}_{2}{ }^{2+}, \mathrm{B}\right) \mathrm{Cd}^{2+} \mathrm{pH}$ from 7, ionic strength $1-7 \mathrm{mmol} \mathrm{L}^{-1}$, time $10 \mathrm{~min}$, PHCA $10^{-5} \mathrm{~mol} \mathrm{~L}^{-1}$, injection of $200 \mu \mathrm{L}$ of $\mathrm{Hg}_{2}{ }^{2+}$ and $\mathrm{Cd}^{2+}\left(10^{-4} \mathrm{~mol} \mathrm{~L}^{-1}\right):$ AuNPs, $10 \mathrm{nmol} \mathrm{L}$ 1

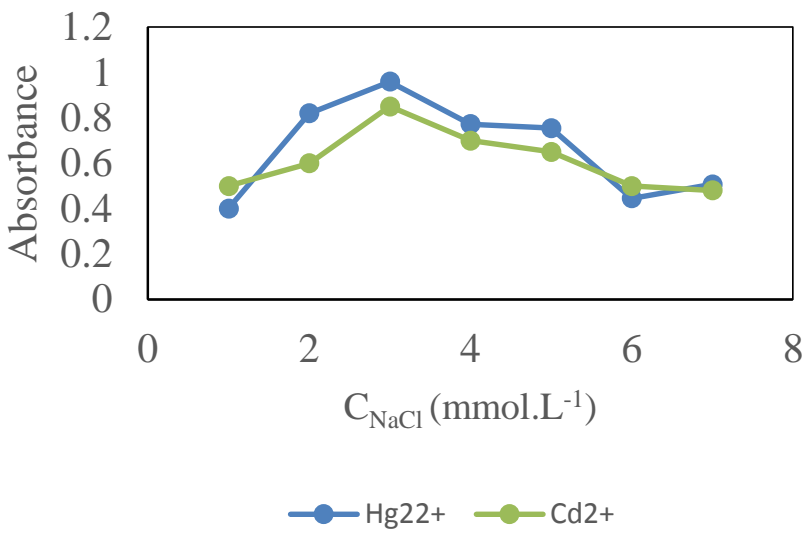

Figure 4. Optimization of $\mathrm{pH}$ for $\mathrm{A}$ ) $\left.\mathrm{Hg}_{2}{ }^{2+}, \mathrm{B}\right) \mathrm{Cd}^{2+}, \mathrm{pH}$ from 4-9, time 10 min, ionic strength $3 \mathrm{mmol} \mathrm{L}^{-1}$ PHCA $10^{-5} \mathrm{~mol} \mathrm{~L}^{-1}$, injection of $200 \mu \mathrm{L}$ of $\mathrm{Hg}_{2}{ }^{2+}$ and $\mathrm{Cd}^{2+}\left(10^{-4} \mathrm{~mol} \mathrm{~L} \mathrm{~L}^{-1}\right)$ : AuNPs, $10 \mathrm{nmol} \mathrm{L}^{-1}$

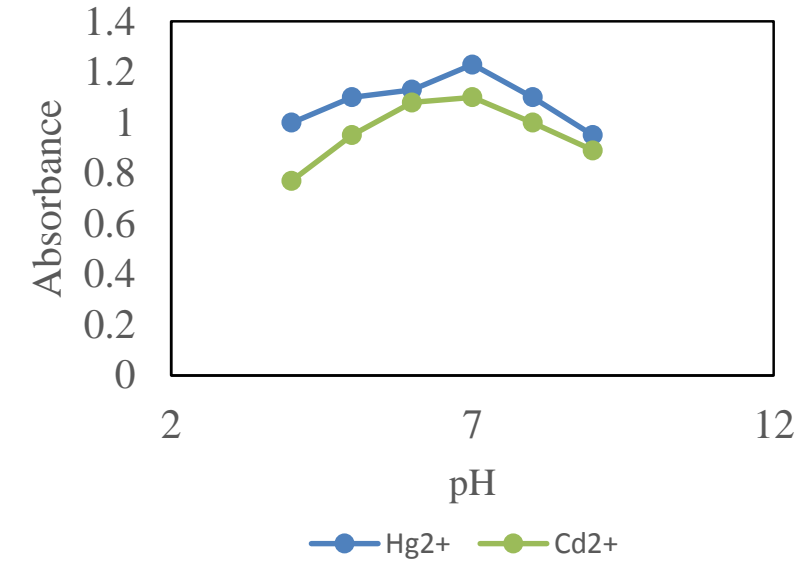


Figure 5. Optimization of $\mathrm{pH}$ for A) $\left.\mathrm{Hg}_{2}{ }^{2+}, \mathrm{B}\right) \mathrm{Cd}^{2+}$ $\mathrm{pH}$ from 7, time 5-25 min, ionic strength $3 \mathrm{mmol} \mathrm{L}^{-1}$

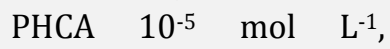
injection of $200 \mu \mathrm{L}$ of $\mathrm{Hg}_{2}{ }^{2+}$ and $\mathrm{Cd}^{2+}\left(10^{-4} \mathrm{~mol}\right.$ $\mathrm{L}^{-1}$ ): AuNPs, $10 \mathrm{nmol} \mathrm{L}^{-1}$

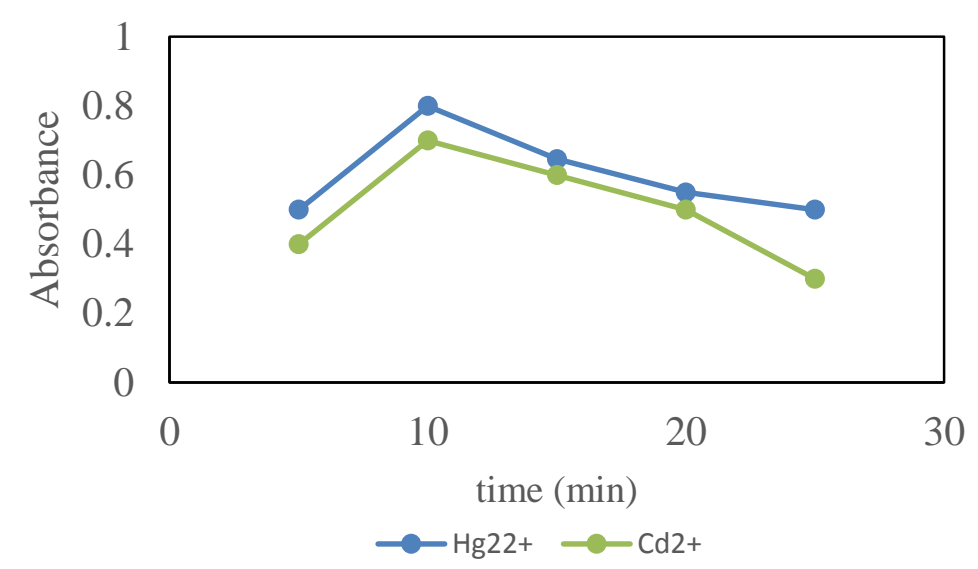

Figure 6. Change in absorbance of AuNPs at 520 and $660 \mathrm{~nm}$ with time, injection of $200 \mu \mathrm{L}$ of $\mathrm{Hg}_{2}{ }^{2+}$, and $\mathrm{Cd}^{2+}\left(10^{-4}\right.$ $\mathrm{mol} \mathrm{L}^{-1}$ ): in each optimum condition of these species: ionic strength 3 mmol $\mathrm{L}^{-1}$, time $10 \mathrm{~min}$, PHCA $10^{-5} \mathrm{~mol} \mathrm{~L}^{-1}$, $\mathrm{pH}$ of 7: AuNPs, $10 \mathrm{nmol} \mathrm{L}^{-1}$
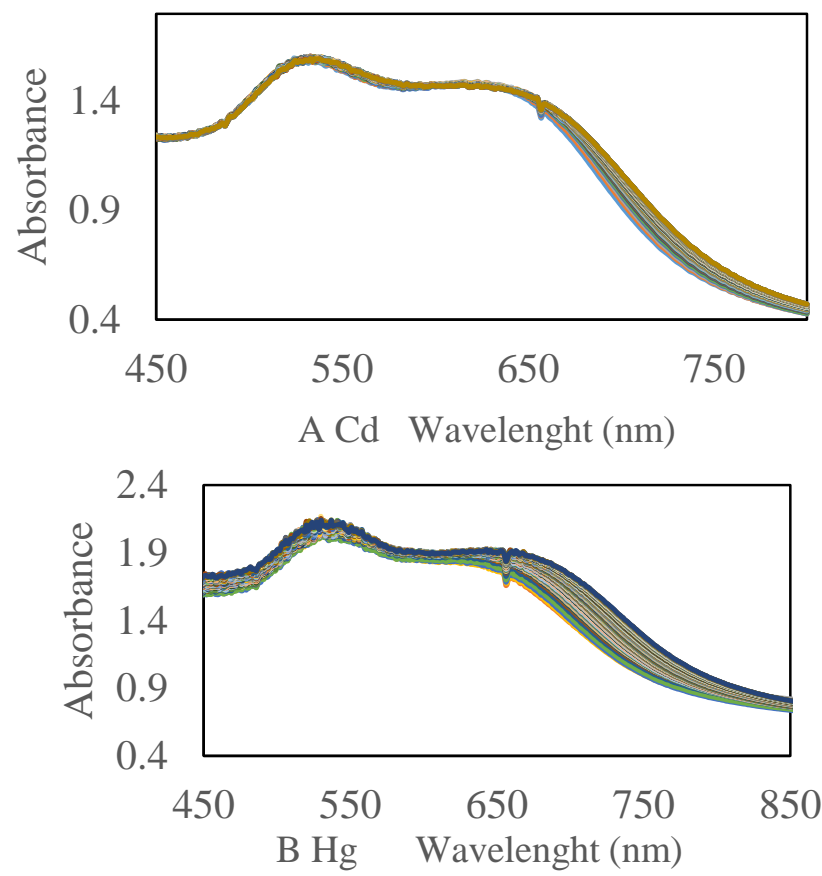

The correlation between the different calibration samples was avoided since collinear component in the training set data had tendency to cause under-fitting in the PLS models [38] (Figure 6 and 7).

\section{Linear range of calibration curves}

For these purpose, under the optimum experimental conditions, a typical calibration curve was obtained for the determination of $\mathrm{Hg}_{2}{ }^{2+}$ and $\mathrm{Cd}^{2+}$ by plotting absorbance ratio $\left(A_{660} / A_{520}\right)$ signal vs. ions concentrations. The calibration curve was linear in the range of $3.33 \times 10^{-5}-3.33 \times 10^{-}$ ${ }^{6} \mathrm{~mol} \mathrm{~L}^{-1}$ and $2.0 \times 10^{-5}-1.0 \times 10^{-6} \mathrm{~mol} \mathrm{~L}^{-1}$ with 
$\mathrm{y}=27334 \mathrm{x}+0.0784\left(\mathrm{R}^{2}=0.995\right)$ and $\mathrm{y}=$ $36737 x+0.2662\left(R^{2}=0.9901\right)$ (Figure 8). The detection limit was $1.21 \times 10^{-7}$ and 0.5 $\times 10^{-7} \mathrm{~mol} \mathrm{~L}^{-1}(\mathrm{n}=5)$ for $\mathrm{Hg}_{2}{ }^{2+}$ and $\mathrm{Cd}^{2+}$, respectively. Table 1 and 2 , show validation parameters and comparison between the results obtained by the present method with those obtained by some other methods for the determination of these substances. As compared in Table 2, the present method has a good detection limit and the linear range compared with electrochemical atomic absorption spectrometry (ETAAS), design of regulations concerning health protection, inductively coupled plasma mass spectrometry (ICP-MS), electro - thermal vaporization inductively coupled plasma mass spectrometry (EVICP-MS) and atomic absorption spectrometry (AAS) method [3942].

\section{Simultaneously determination of $\mathbf{H g}_{2}{ }^{2+}$ and $\mathrm{Cd}^{2+}$}

As mentioned, in order to select the number of factors in the PLS algorithm a crossvalidation method of leaving out one sample at a time, was employed. The increase in the intensity of the absorbance in $660 \mathrm{~nm}$ was directly related to the level of $\mathrm{Hg}_{2}{ }^{2+}$ and $\mathrm{Cd}^{2+}$ in the sample (Figure 6). The rate of aggregation of the synthesized AuNPs by the use of citrate was correlated with the level of
$\mathrm{Hg}_{2}{ }^{2+}$ and $\mathrm{Cd}^{2+i n}$ different constants. The calibration and prediction sets were collected by monitoring the increasing rate of absorbance in $660 \mathrm{~nm}$ and were used for PLS process. For the mentioned set including 19 sample kinetic profiles, PLS $_{-1}$ and $\mathrm{PLS}_{-2}$ algorithms were performed and using these calibrations the amount of the samples left out during the calibration process were calculated. Changes in PRESS of $\mathrm{PLS}_{-2}$ calibration as a function of the number of PLS latent variables are given in Figure 9. As can be seen 3 components were enough to construct the $\mathrm{PLS}_{-2}$ model. Nonlinearity in the absorbanceconcentration relationship and interaction between the factors can be considered as the other source of chemical factors.

The predicted values of $\mathrm{Hg}_{2}{ }^{2+}$ and $\mathrm{Cd}^{2+}$ levels in the calibration and prediction samples and their corresponding relative errors of prediction were listed in Tables 35. It was observed that the predicted values are very close to the actual amounts and the relative prediction errors are almost lower than $6.0 \%$. This confirms the success of the PLS regression for accurate prediction of $\mathrm{Hg}_{2}{ }^{2+}$ and $\mathrm{Cd}^{2+}$ amounts in samples. It will be beneficial to compare the results of PLS -1 and PLS-2 multivariate calibration resulted in a more appropriate model. 
Figure 7. Change in absorbance of AuNPs at 520 and $660 \mathrm{~nm}$ with time, injection of $200 \mu \mathrm{L}$ of $\mathrm{Hg}_{2}{ }^{2+}$, and $\mathrm{Cd}^{2+}\left(10^{-4} \mathrm{~mol} \mathrm{~L}^{-1}\right)$ : in each optimum condition of these species: ionic strength $3 \mathrm{mmol} \mathrm{L}^{-1}$, time $10 \mathrm{~min}$, PHCA $10^{-5} \mathrm{~mol} \mathrm{~L}^{-1}$, pH of 7 : AuNPs, $10 \mathrm{nmol} \mathrm{L}^{-1}$
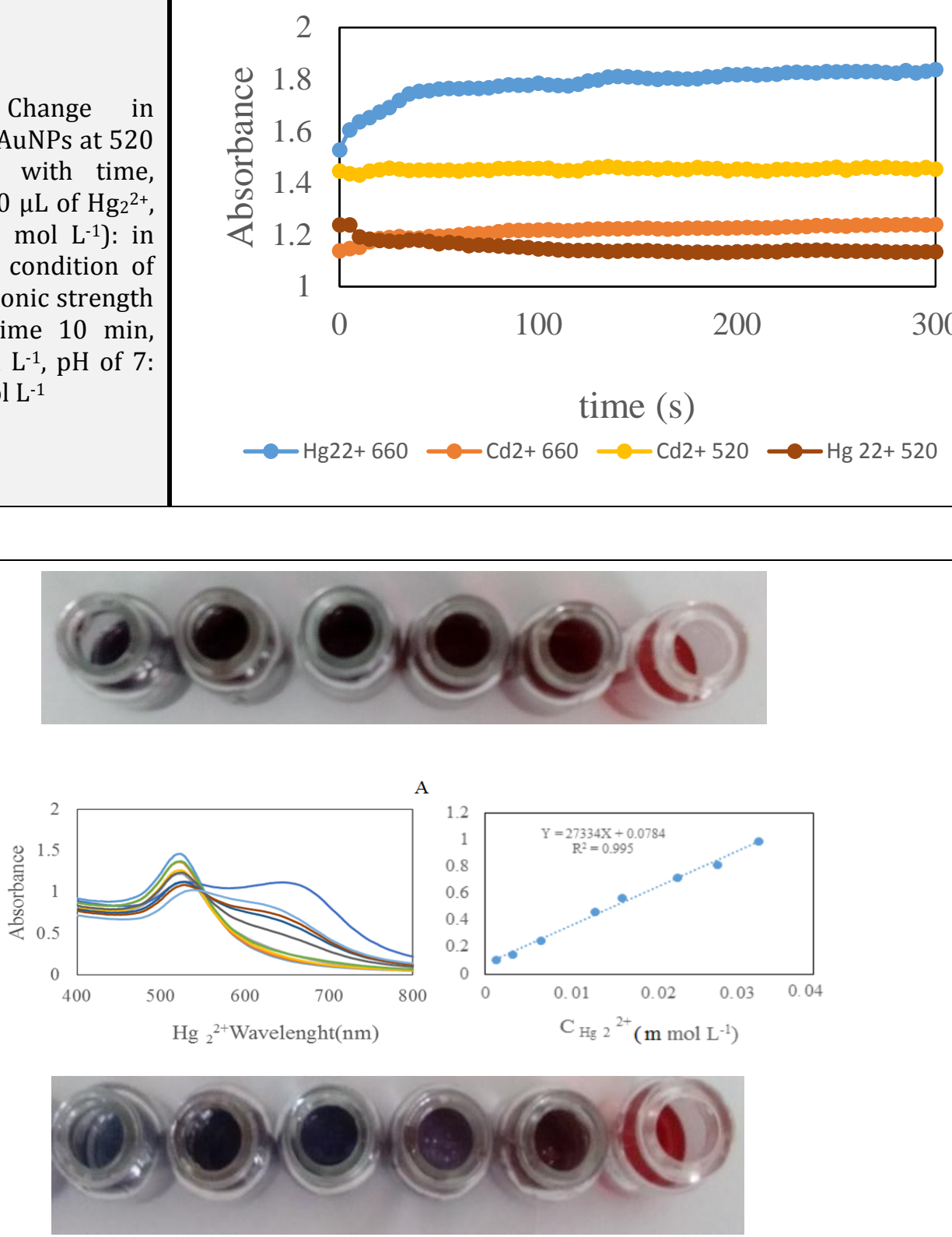

B
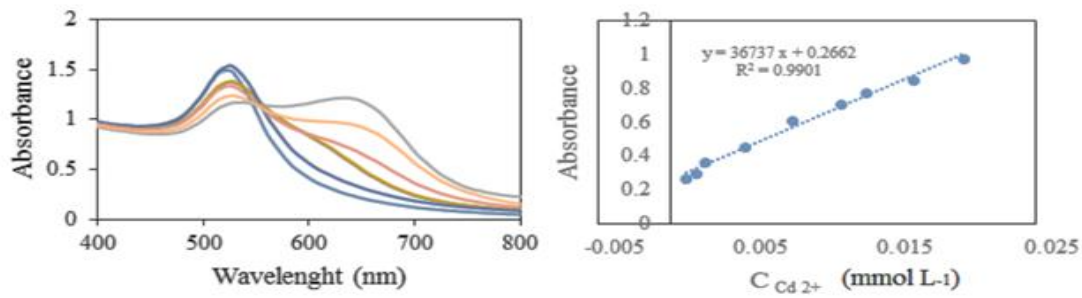

Figure 8. Calibration curve of $\mathrm{Hg}_{2}{ }^{2+}$ and $\mathrm{Cd}^{2+}$ in optimum condition: ionic strength $3 \mathrm{mmol} \mathrm{L}^{-1}$, time 10 min, PHCA $10^{-5} \mathrm{~mol} \mathrm{~L}^{-1}$, pH of 7: AuNPs, $10 \mathrm{nmol} \mathrm{L}^{-1}$ 
Table 1. Method validation parameters for $\mathrm{Hg}_{2}{ }^{2+}$ and $\mathrm{Cd}^{2+}$, respectively

\begin{tabular}{cc}
\hline Equation & $\mathrm{Y}=27334 \mathrm{X}+0.0784$ and $\mathrm{y}=36737 \mathrm{x}+0.2662$ \\
$\mathrm{R}^{2}$ & 0.995 and 0.9901 \\
LoD & $1.21 \times 10^{-7}$ and $0.5 \times 10^{-7} \mathrm{~mol} \mathrm{~L}^{-1}$ \\
Linear range & $3.33 \times 10^{-5}-3.33 \times 10^{-6}$ and $2.0 \times 10^{-5}-1.0 \times 10^{-6} \mathrm{~mol} \mathrm{~L}^{-1}$ \\
\hline
\end{tabular}

Table 2. Characteristic performance data obtained by spectrophotometric method and other techniques for determination of $\mathrm{Hg}_{2}{ }^{2+}$ and $\mathrm{Cd}^{2+}$

\begin{tabular}{|c|c|c|c|}
\hline $\begin{array}{c}\text { Detection } \\
\text { method }\end{array}$ & $\begin{array}{c}\text { Linear range } \\
\left(\mathrm{mol} \mathrm{L}^{-1}\right)\end{array}$ & $\begin{array}{c}\text { LoD } \\
\left(\mathrm{mol} \mathrm{L}^{-1}\right)\end{array}$ & Reference \\
\hline \multicolumn{4}{|l|}{ A) $\mathrm{Cd}^{2+}$} \\
\hline ETAAS a & $1-100 \times 10^{-6}$ & $0.36 \times 10^{-6}$ & {$[39-40]$} \\
\hline ICP-MS b & $5-350 \times 10^{-6}$ & $1.5 \times 10^{-6}$ & {$[41]$} \\
\hline EVICP-MS c & $\times 10^{-6} 0.1-150$ & $\times 10^{-6} 0.08$ & [42] \\
\hline \multicolumn{4}{|l|}{$\mathrm{B}: \mathrm{Hg}_{2}{ }^{2+}$} \\
\hline ETAAS a & $\times 10^{-6} 2-70$ & $0.48 \times 10^{-6}$ & [39-40] \\
\hline AAS $^{d}$ & $15 \times 10^{-6}-1$ & $0.5 \times 10^{-6}$ & {$[41]$} \\
\hline EVICP-MS c & $120 \times 10^{-6}-0.5$ & 6 & [42] \\
\hline spectrophotometric method & $\begin{array}{l}3.33 \times 10^{-5}-3.33 \times 10^{-6} \text { and } \\
2.0 \times 10^{-5}-1.0 \times 10^{-6} \mathrm{~mol} \mathrm{~L}^{-1} \\
\quad \text { for } \mathrm{Hg}_{2}{ }^{2+} \text { and } \mathrm{Cd}^{2+}\end{array}$ & $\begin{array}{c}0.02 \times 10^{-} \\
1.21 \times 10^{-7} \text { and } 0.5 \times 10^{-} \\
{ }^{7} \mathrm{~mol} \mathrm{~L}^{-1} \\
\text { For } \mathrm{Hg}_{2}{ }^{2+} \text { and } \mathrm{Cd}^{2+}\end{array}$ & This work \\
\hline
\end{tabular}

\footnotetext{
a: Electrochemical atomic absorption spectrometry

b: inductively coupled plasma mass spectrometry

c: electro thermal vaporization inductively coupled plasma mass spectrometry

$\mathrm{d}$ : atomic absorption spectrometry
}

For this comparison and the validation of the models; some statistical parameters including root mean square error of prediction (RMSEP), root mean square error of cross validation (RMSECV) and root mean square error of calibration (RMSEC) were calculated. The calculated statistical parameters are given in Table 5. One can see from Tables 3 and 4 that the calibration and prediction results of PLS are more consistent than those of univariate calibration.

\section{Interference study}

The influences of foreign coexisting substances such as naproxen, ascorbic acid, tramadol, codeine, acetaminophen, saccharides, amino acids and ions were tested. As listed in Table 6, some of the examined coexisting substances had remarkable interference on the assay. From the results, among the tested substance $\mathrm{K}^{+}$, $\mathrm{Na}^{+}, \mathrm{NO}^{3-}, \mathrm{I}-\mathrm{Cl}^{-}, \mathrm{Mg}^{2+}, \mathrm{Fe}^{3+}$ and $\mathrm{Ca}^{2+}$ can be allowed with relatively higher concentrations but $\mathrm{NH}_{2} \mathrm{OH}, \mathrm{Mn}^{2+}, \mathrm{SO}_{4}{ }^{2-}$, $\mathrm{Ca}^{2+}, \mathrm{Zr}^{2+}, \mathrm{Co}^{2+}, \mathrm{Zn}^{2+}, \mathrm{Ni}^{2+}, \mathrm{Al}^{3+}, \mathrm{Fe}^{2+}, \mathrm{Pb}^{2+}$ and $\mathrm{Cu}^{2+}$ can only be allowed with relatively low concentrations. The allowed concentrations of these interfering substances however, were still rather higher than that of $\mathrm{Hg}_{2}{ }^{2+}$ and $\mathrm{Cd}^{2+}$ which indicated that this method 
had a good selectivity between ions.

Table 3. The level of reference value of $\mathrm{Hg}_{2}{ }^{2+}$ and $\mathrm{Cd}^{2+}$ in the prediction set by PLS modeling of UV-Vis spectra in $660 \mathrm{~nm}$.

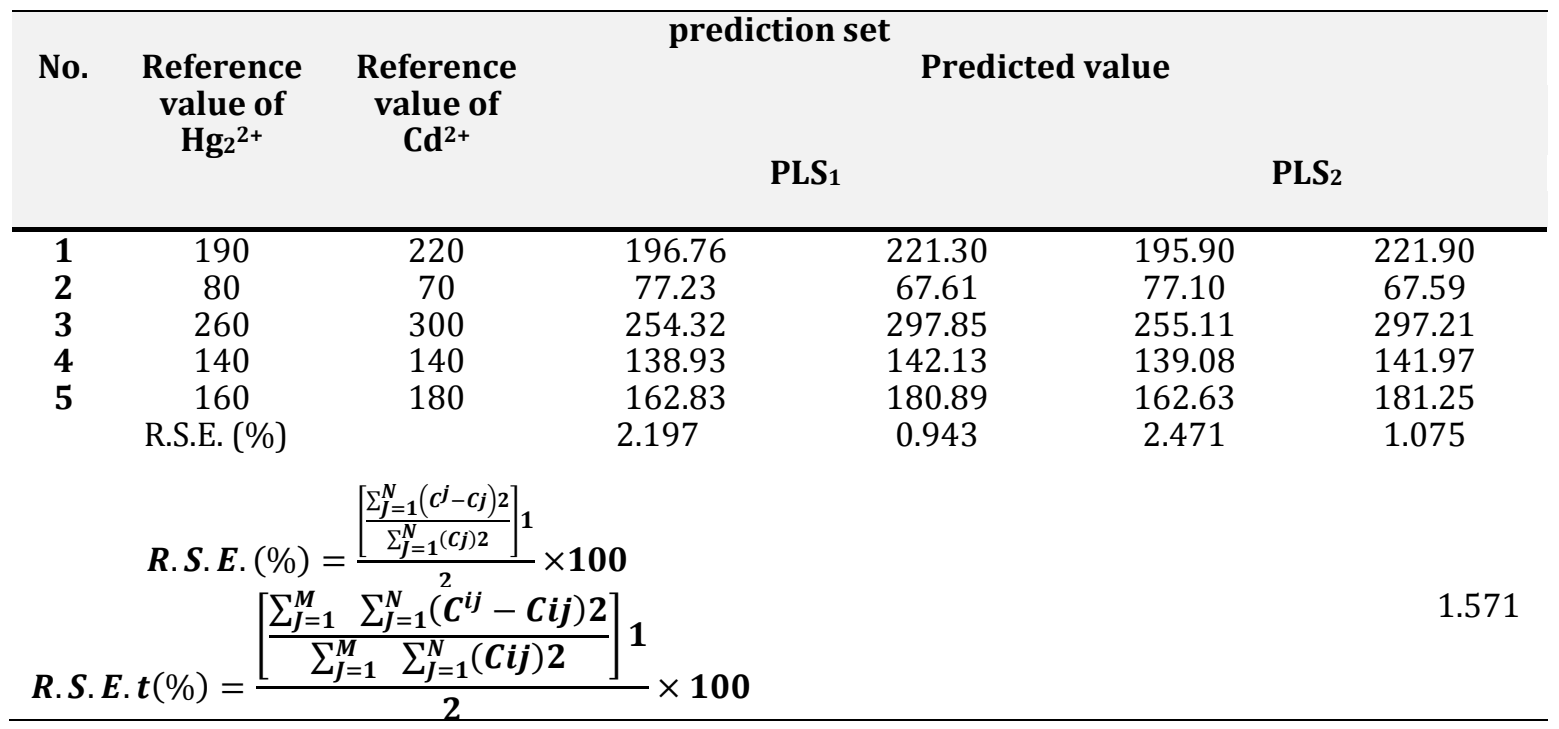

Table 4. The level of reference value of $\mathrm{Hg}_{2}{ }^{2+}$ and $\mathrm{Cd}^{2+}$ in the calibration set by PLS modeling of UV-Vis spectra in $660 \mathrm{~nm}$

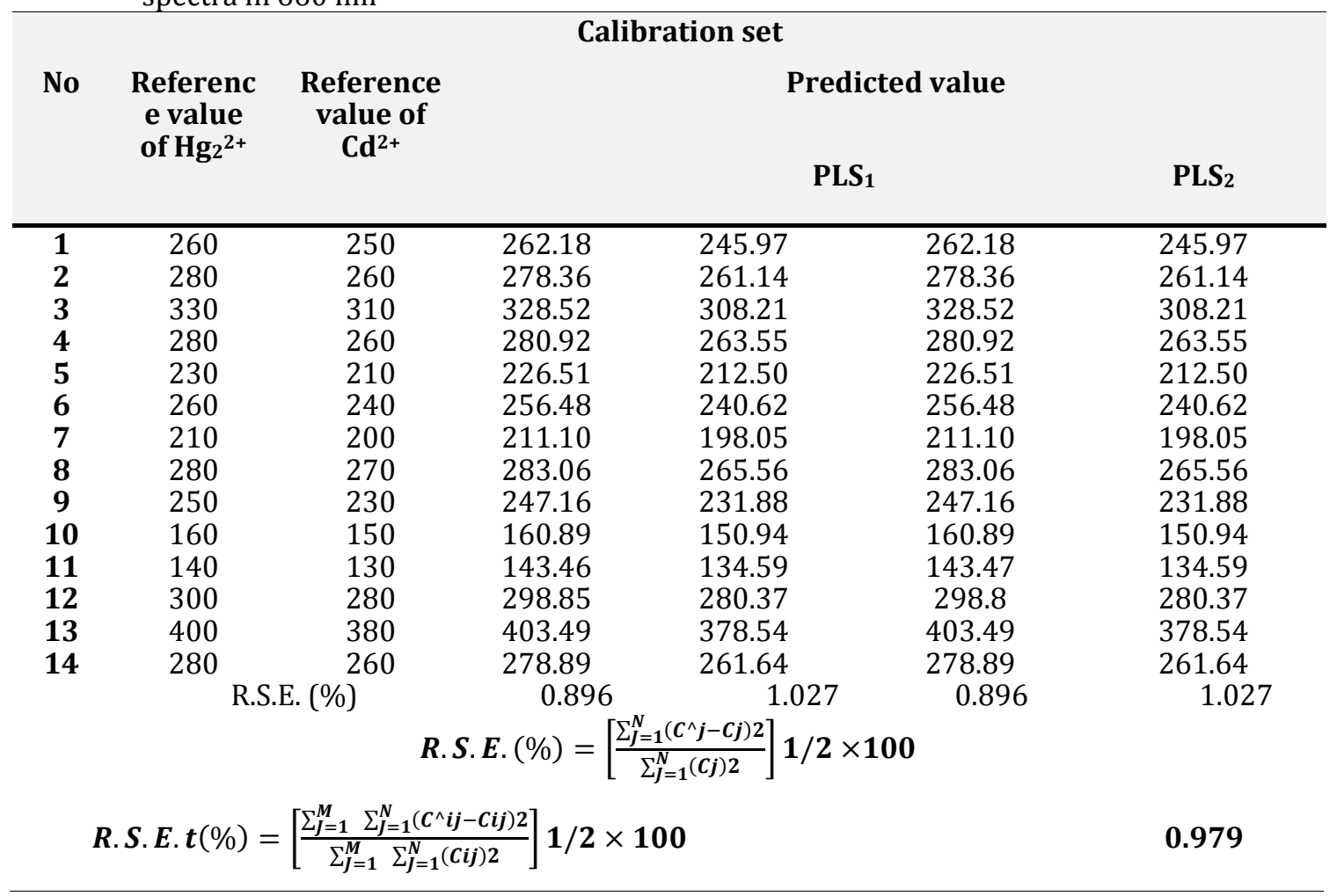


Table 5. Statistical parameters from $\mathrm{PLS}_{1}$ and $\mathrm{PLS}_{2}$ calibration models

\begin{tabular}{ccc}
\hline & Model of prediction & \\
\hline Statistical parameters & PLS $\mathbf{1}(\mathbf{\%})$ & PLS $(\%)$ \\
RMSEP & 3.99 & 3.89 \\
RMSECV & 2.58 & 2.61 \\
RMSEC & 5.12 & 5.16 \\
\hline
\end{tabular}
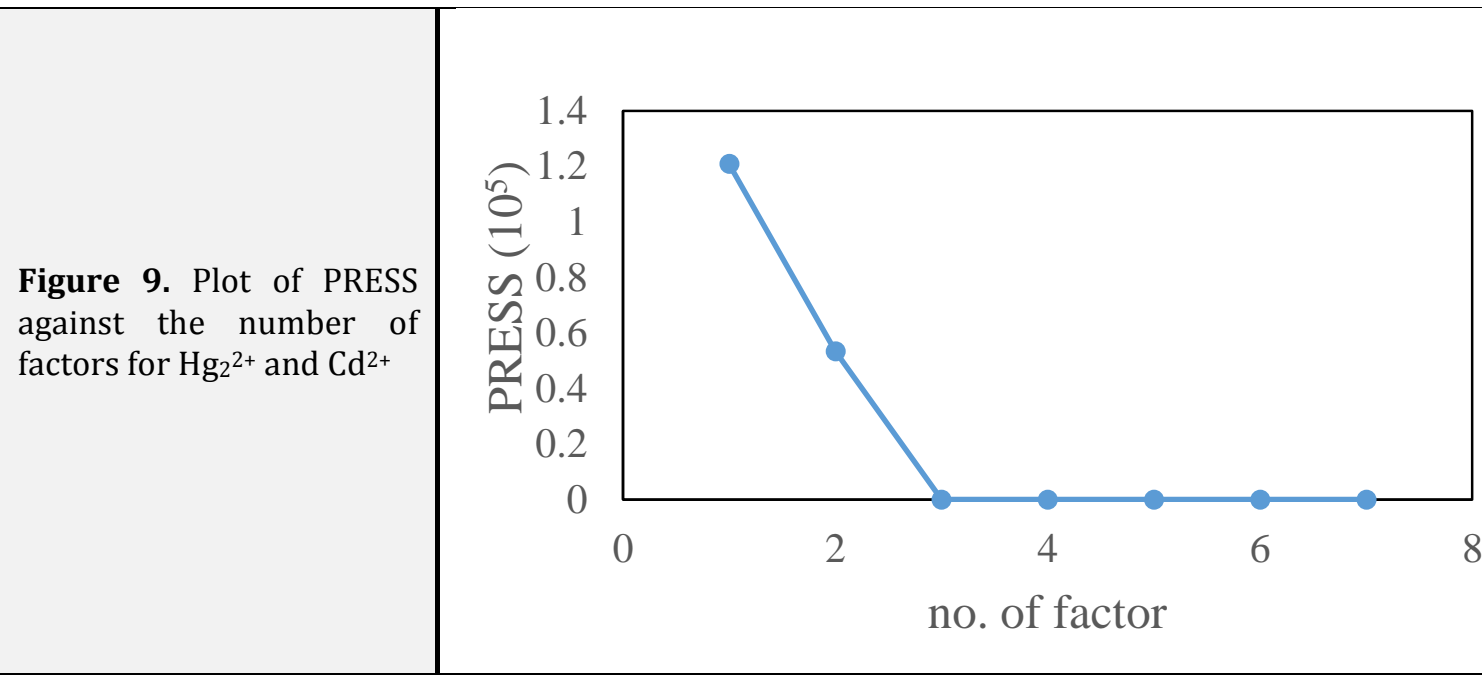

Table 6. Tests for interferer substance on simultaneous determination of $\mathrm{Hg}_{2}{ }^{2+}$ and $\mathrm{Cd}^{2+}$ in optimum condition: ionic strength $3 \mathrm{mmol} \mathrm{L}^{-1}$, time $10 \mathrm{~min}$, PHCA 10-5 $\mathrm{mol} \mathrm{L}^{-1}$, pH of 7: AuNPs, $10 \mathrm{nmol}$ $\mathrm{L}^{-1}$

\begin{tabular}{cc}
\hline Substance & $\begin{array}{c}\text { Tolerable concentration } \\
\text { (analyte }\left(\mathrm{Hg}^{2+}: \mathbf{C d}^{2+} \text { ) } \text { :interfering }\right. \\
\text { ion }) \text { ) }\end{array}$ \\
\hline $\mathrm{K}^{+}, \mathrm{Na}^{+}, \mathrm{NO}^{3-}, \mathrm{I}^{-}, \mathrm{Cl}^{-}, \mathrm{Mg}^{2+}, \mathrm{Fe}^{3+}, \mathrm{Ca}^{2+}$ & $1: 1: 300$ \\
$\mathrm{NH}_{2} \mathrm{OH}, \mathrm{Mn}^{2+}, \mathrm{SO}_{4}{ }^{2-}, \mathrm{Ca}^{2+}, \mathrm{Zr}^{2+}, \mathrm{Co}^{2+}, \mathrm{Zn}^{2+}, \mathrm{Ni}^{2+}, \mathrm{Al}^{3+}, \mathrm{Fe}^{2+}$, & $1: 1: 100$ \\
$\mathrm{Cu}^{2+}, \mathrm{Pb}^{2+}$ & \\
\hline
\end{tabular}

Table 7. Analysis of Zarineh and Simineh rivers and Urmia lake water samples for $\mathrm{Hg}_{2}{ }^{2+}$ and $\mathrm{Cd}^{2+}$ ionic strength $3 \mathrm{mmol} \mathrm{L}^{-1}$, time $10 \mathrm{~min}$, PHCA $10^{-5} \mathrm{~mol} \mathrm{~L}^{-1}$, $\mathrm{pH}$ of 7: AuNPs, $10 \mathrm{nmol} \mathrm{L}^{-1}$

\begin{tabular}{|c|c|c|c|c|c|c|}
\hline \multirow{2}{*}{ sample } & \multicolumn{2}{|c|}{$\operatorname{Add}\left(\mathrm{mol} \mathrm{L}^{-1}\right) 10^{-6}$} & \multicolumn{2}{|c|}{ Found(mol L-1) $10^{-6}$} & \multicolumn{2}{|c|}{ (\%) Recovery } \\
\hline & $\mathrm{Hg}_{2}{ }^{2+}$ & $\mathrm{Cd}^{2+}$ & $\mathrm{Hg}_{2}{ }^{2+}$ & $\mathrm{Cd}^{2+}$ & $\mathrm{Hg}_{2}{ }^{2+}$ & $\mathrm{Cd}^{2+}$ \\
\hline \multirow{4}{*}{ Urmia lake } & 0 & 0 & 0.31 & 0.4 & 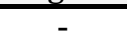 & - \\
\hline & 4.0 & 4.0 & 3.91 & 4.03 & 90.0 & 90.75 \\
\hline & 5.0 & 5.0 & 5.32 & 4.92 & 100.2 & 90.4 \\
\hline & 6.0 & 6.0 & 6.3 & 6.8 & 99.83 & 106.7 \\
\hline \multirow{4}{*}{ Zarineh river } & 0 & 0 & 0.2 & 0.0018 & - & . \\
\hline & 4.0 & 4.0 & 3.86 & 4.03 & 91.5 & 100.3 \\
\hline & 5.0 & 5.0 & 4.78 & 5.06 & 91.6 & 100.84 \\
\hline & 6.0 & 6.0 & 5.84 & 6.32 & 94.0 & 105.03 \\
\hline \multirow{4}{*}{ Simineh river } & 0 & 0 & 0.02 & 0.04 & - & - \\
\hline & 4.0 & 4.0 & 4.05 & 3.9 & 100.75 & 96.5 \\
\hline & 5.0 & 5.0 & 5.19 & 5.41 & 103.4 & 107.4 \\
\hline & 6.0 & 6.0 & 6.20 & 5.97 & 103.0 & 98.83 \\
\hline
\end{tabular}




\section{Real sample analysis}

In order to test the applicability of the proposed method, it was used to indicate the $\mathrm{Hg}_{2}{ }^{2+}$ and $\mathrm{Cd}^{2+}$ in spiked water samples. The constructed PLS model was applied to estimate the concentration of $\mathrm{Hg}_{2}{ }^{2+}$ and $\mathrm{Cd}^{2+}$ in these spiked samples. The results showed good recoveries (90.0-107.4 \%) (Table 7). The results demonstrated the potential applicability of this method for simultaneous detection of $\mathrm{Hg}_{2}{ }^{2+}$ and $\mathrm{Cd}^{2+}$ in real samples.

\section{Conclusion}

The LSPR of the AuNPs synthesized through the reduction of gold ion with citrate and modified by PHCA, as a novel analytical tool to determineHg $2^{2+}$ and $\mathrm{Cd}^{2+}$. A direct relationship was found between the aggregation rates recorded in $\lambda_{\max }$ at about 520 and $620 \mathrm{~nm}$ and concentrations of $\mathrm{Hg}_{2}{ }^{2+}$ and $\mathrm{Cd}^{2+}$. Multivariate calibration modeling of the kinetic absorbance data by the use of PLS regression produced accurate results and the relative prediction errors were almost lower than 5\%. In comparison with available analytical methods for simultaneous determination of $\mathrm{Hg}_{2}{ }^{2+}$ and $\mathrm{Cd}^{2+}$, the proposed method had following advantages: (i) it needs smaller amounts of reagents; (ii) it is simple, fast, and economic; and (iii) in contrast to chromatographic methods, it doesnot need any expensive apparatus.

\section{References}

[1]. K. Naeem, W. Yawar, P. Akhter, AsiaPacific J. Chem. Engin., 2012, 7, 295-299.

[2]. T. Davous, Standard Atomic Weights, Commission on Isotopic Abundances and Atomic Weights; $2^{\text {nd }}$ ed., Springer: Dordrecht, London, 2013.

[3]. D.R. Lide, Magnetic susceptibility of the elements and inorganic compounds, CRC Handbook of Chemistry and Physics CRC Press; 86th ed., Boca Raton: FL, London, 2005.

[4]. H. Morrow, Cadmium and Cadmium Alloys, Encyclopedia of Chemical Technology; John Wiley \& Sons: 2010.

[5]. A.F. Wells, Structural Inorganic Chemistry; 3d ed., Oxford Science Publications: 1962.

[6]. N. Greenwood Norman, A. Earnshaw, Chemistry of the Elements, 2nd ed., Butterworth-Heinemann: 1997.

[7]. K. Brodersen, G. Göbel, G. Liehr, für anorg. Und allgem. Chem., 1989, 575, 145149.

[8]. I.D. Brown, B.D. Cutforth, G.D. Colin, J.R. Gillespie, R.P. Ireland, J.E. Vekris, Can. J. Chem., 1974, 52, 791-794.

[9]. I.D. Brown, R.J. Gillespie, K.R. Morgan, Z. Tun, P.K. Ummat, Inorg. Chem., 1984, 26, 4506-4508.

[10]. S. Bakirdere, M. Yaman, Environ. Monit. 
Assess., 2008, 136, 401-410.

[11]. H.B. Ulusoy, M. Akcay, R. Gürkan, Talanta, 2011, 85, 1585-1588.

[12]. J. Sardans, F. Montes, J. Peñuelas, Spectrochim. Acta., 2010, 65, 97-99.

[13]. V.L. Atz, D. Pozebon, Atomic Spectr., 2009, 30, 82-88.

[14]. F. Chen, D.D. Xu, X.P. Tang, J. Cao, Y.T. Liu, J. Deng, Spect. And Spectr. Anal., 2012, 32, 239-241.

[15]. M. Bingöl, G. Yentür, B. Er, A.B. Öktem, Czech J. Food Sci., 2010, 28, 213-215.

[16]. S. Dilio, C. Majorani, F. Petrucci, N. Violante, O. Senofonte, Anal. Meth., 2010, 2, 2049-2055.

[17]. M.G. Minnich, D.C. Miller, P.J. Parsons, Spectrochim. Acta, 2008, 63, 389-390.

[18]. M. Yaman, M. Güneş, S. Bakirdere, Bull. Environ. Contaminal. Toxicol., 2003, 70, 437439.

[19]. M. Yaman, S. Bakirdere, Microchim. Acta., 2003, 141, 47-49.

[20].B. Liu, H. Tan, Y. Chen, Microchim. Acta. 2013, 180, 331-333.

[21]. W. Chansuvarn, A. Imyim, Microchim. Acta.2012, 176, 65-68.

[22]. D. Vilela, M.C. Gonzalez, A. Escarpa, Anal. Chim. Acta.2012, 751, 24-26.

[23]. C.S. Weisbecker, M.V. Merritt, G.M. Whitesides, Langmuir, 1996, 12, 3763-3766. [24]. S. Peschel, G.A. Schmid, Chem. Int. Ed. Engl., 1995, 34, 1442-1445.

[25]. P. Alivisatos, Nat. Biotechnol., 2004, 22,
47-49.

[26]. O. Abbas, C. Rebufa, N. Dupuy, A. Permanyer, J. Kister, Fuel., 2011, 98, 5-9.

[27]. K.M.G. Lima, I.M. Raimundo, M.F. Pimentel, Sens. Actuators B, 2011, 69, 160 165.

[28]. R.M. Balabin, E.I. Lomakina, R.Z. Safieva, Fuel, 2011, 90, 2007-2009.

[29]. A.R. Coscione, J.C, Andeade, R.J. Poppi, C. Mello, Anal. Chim. Acta, 2000, 423, 31-33.

[30]. D.L. Massart, B.G.M. Vandeginste, L.M.C. Buydens, S.D.E. Jong, P.J. Lewi, Handbook of chemometrics and qualimet-rics. Part A.; Elsevier Science: 1997.

[31]. M. Bahram, T. Madrakian, S. Alizadeh, J. Pharm. Anal. 2017, 7, 411-416.

[32]. P. Khatri Om, K. Murase, H. Sugimura, Langmuir, 2008, 24, 3787-3789.

[33]. J. Maat, R. Regeling, C.J. Ingham, Langmuir, 2011, 27, 13606-13608.

[34]. A.T. Yordanov, N.J. Wolf, E.M. Georgiev, H.F. Koch, O.M. Falana, D.M. Roundhill, Comments Inorg. Chem., 1999, 20, 163-165.

[35]. I. Kazanga, S. Tameni, A. Piccinotti, I. Floris, G. Zanchetti, A. Polettini, Forensic. Sci. Int., 2012, 215, 46-48.

[36]. J.J. Storhoff, A.A. Lazarides, R.C. Mucic, C.A. Mirkin, R.L. Letsinger, G.C. Schatz, J. Am. Chem. Soc., 2000, 122, 4640-4644.

[37]. G. Svela, Quantitative analysis of inorganic chemistry; Vogel, six ed., University of science and Technology: Tehran, Iran, 2010. 
[38]. T. Madrakian, A. Afkhami, M. Borazjani, M. Bahram, Spectrochimica Acta. Part A, 2005, 61, 2988-2990.

[39]. J. Sardans, F. Montes, J. Peñuela, Spectrochimica Acta Part B, 2010, 65, 97-99. [40]. B. Benes, V. Spěvácková, J. Smíd, Cent.
Eur. J. Public. Health.2002, 10, 3-5.

[41]. J. Retka, A. Maksymowicz, D. Karmasz, accum. food crops. 2011, 4, 373-375.

[42]. S.M. Mai, D. Pozebona, A. José Curtius, J. Anal. Spectrom.2003, 18, 330-335.

How to cite this manuscript: Sakineh Alizadeh*, Tayyebeh Madrakian, Morteza Bahram, Selective and Sensitive Simultaneous Determination of Mercury and Cadmium based on the Aggregation of PHCA Modified- AuNPs in West Azerbaijan Regional Waters, Adv. J. Chem. $A, 2019,2(1), 57-72$. 